\title{
SÍTIO BAIXADÃO: UM NOVO SÍTIO ARATU NO NORTE PAULISTA
}

\author{
André Penin* \\ Paulo De Blasis**
}

No mês de abril de 2006 foi realizada uma prospecção arqueológica, de caráter local e expedito, ao longo do limite SW da Estação Ecológica Paulo de Faria, no município de mesmo nome, no extremo norte do estado de São Paulo. Esta prospecção foi feita a pedido do Instituto Florestal, ligado à Secretaria de Meio Ambiente do Estado de São Paulo, que administra a Estação e objetiva ali construir uma base local.

Desde os anos 80 funcionários reportam a presença de vestígios arqueológicos nas proximidades, especialmente ao longo do limite da estação com a fazenda contígua (utilizado como trilha). $\mathrm{O}$ exame prévio de uma borda cerâmica e alguns artefatos polidos, em poder do IF, sugeria a presença de um sítio cerâmico na área. Nesse sentido, o IF nos solicitou um diagnóstico da situação.

Planejou-se, assim, uma breve pesquisa de campo que tinha entre seus objetivos cadastrar no CNSA(Cadastro Nacional de Sítios Arqueológicos) o sítio que se encontra nas cercanias, descrevendo-o e produzindo material informativo básico para uso do IF.

A estação localiza-se no bairro do Baixadão, município de Paulo de Faria (Fig. 1). A partir do núcleo urbano deste município, o acesso à área é feito através da rodovia Valdemar Lopes Ferraz no sentido de Riolândia por 15km; depois, entra-se na estrada municipal do Córrego Fundo, prosseguindo por mais 13km. Esta estrada municipal faz a divisa entre a Estação Ecológica e propriedades adjacentes (Fig. 2), onde foram reportados, nos anos 80, os vestígios arqueológicos anteriormente relacionados.

$\left({ }^{*}\right)$ Museu de Arqueologia e Etnologia da Universidade de São Paulo. Doutorando em Arqueologia apenin@gmail.com $(* *)$ Museu de Arqueologia e Etnologia da Universidade de São Paulo.deblasis@usp.br
O terreno estudado (UTM 22K 0653053/ 779243) é uma vertente retilínea com uma leve declividade - de 5 a 12\% - sendo que a inclinação, no sentido SE, é mais acentuada na área pertencente à Estação Ecológica. Na área da reserva particular adjacente, o declive suaviza gradativamente até alcançar um brejo, cujas águas são afluentes do córrego do Mundinho.

A vegetação que recobre a região é a Floresta Estacional Semidecidual, presente em toda a Estação Ecológica. Apesar de o entorno da área ser composto por plantações, o que provavelmente contribuiu para certa perda de biodiversidade, trata-se de um local ainda densamente florestado, estando presentes árvores de porte considerável (estágio sucessional secundário avançado). Nos locais em que o terreno é mais aberto, o solo é inteiramente coberto por vegetação em decomposição, o que praticamente impossibilitou a visualização de vestígios arqueológicos em superfície.

A estratégia original consistia em caracterizar o sítio com o mínimo possível de intervenções. A intenção, portanto, era procurar delimitá-lo a partir da dispersão das peças arqueológicas localizadas em superfície. A baixa visibilidade do solo prejudicou este plano, mas a presença de vestígios cerâmicos no local foi atestada por duas árvores caídas, cujas raízes trouxeram consigo o material arqueológico.

A partir da certeza da presença de material arqueológico, foi aberta uma série de poços-teste para delimitar o sítio, seguindo um eixo NW-SE e outro NE-SW. Percebeu-se que o material arqueológico está presente em um local em que a vegetação é um pouco menos densa que a do entorno, e que o sítio como um todo se encontra dentro da reserva particular; foi feita uma série de poços-teste na parte do terreno pertencente à Estação Ecológica, todos arqueologicamente estéreis com sedimento argiloso de coloração vermelha escura (Nitossolo Vermelho).

Como, no entanto, vestígios enterrados foram encontrados ao longo da cerca (limite da estação), 


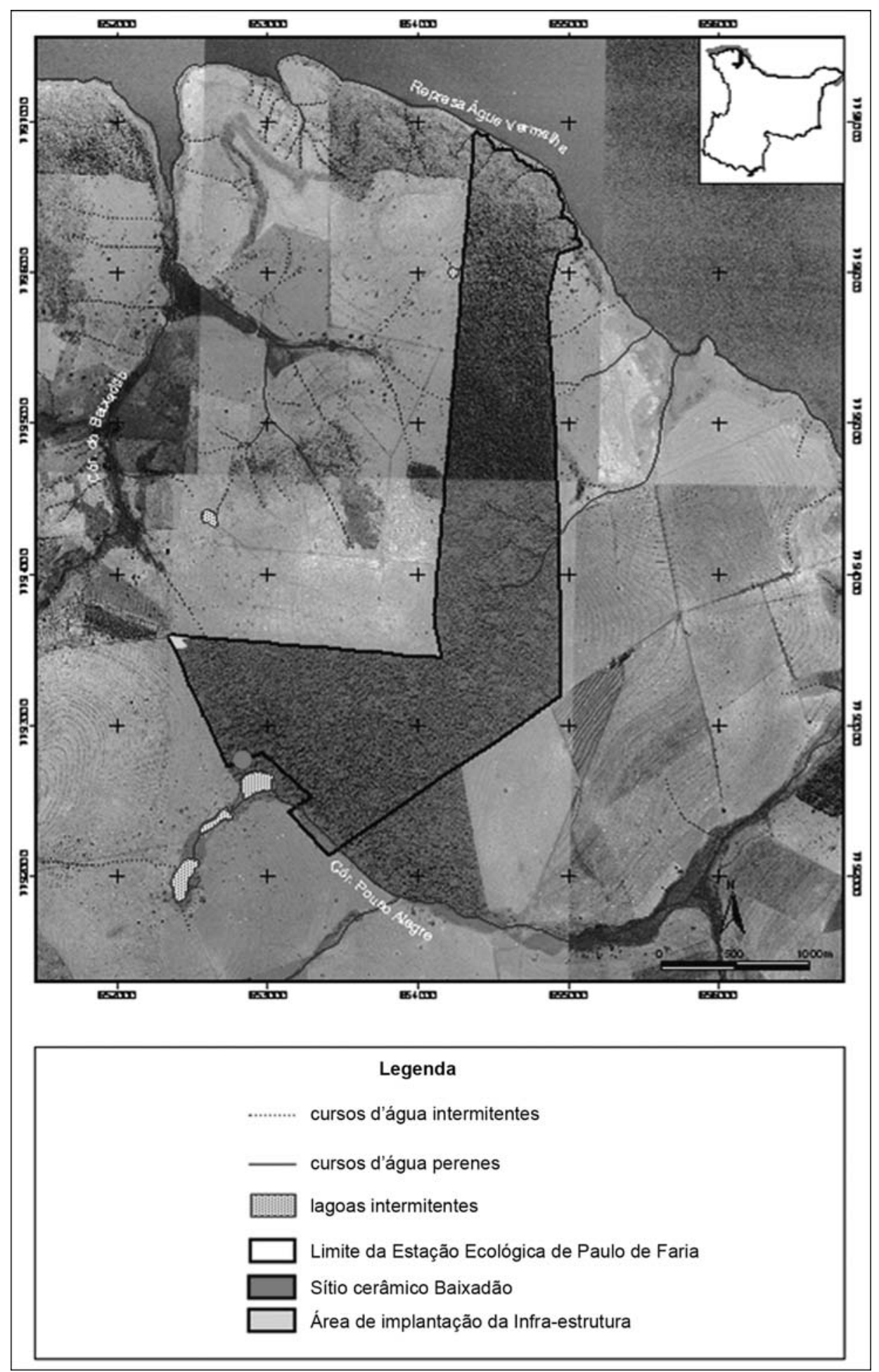

Fig. 1 - Localização das áreas pesquisadas na Estação Ecológica Paulo de Faria. 
PENIN, A.; DE BLASIS, P.A. Sítio Baixadão: um novo sítio Aratu no norte paulista. Rev. do Museu de Arqueologia e Etnologia, São Paulo, 15-16: 449-453, 2005-2006.

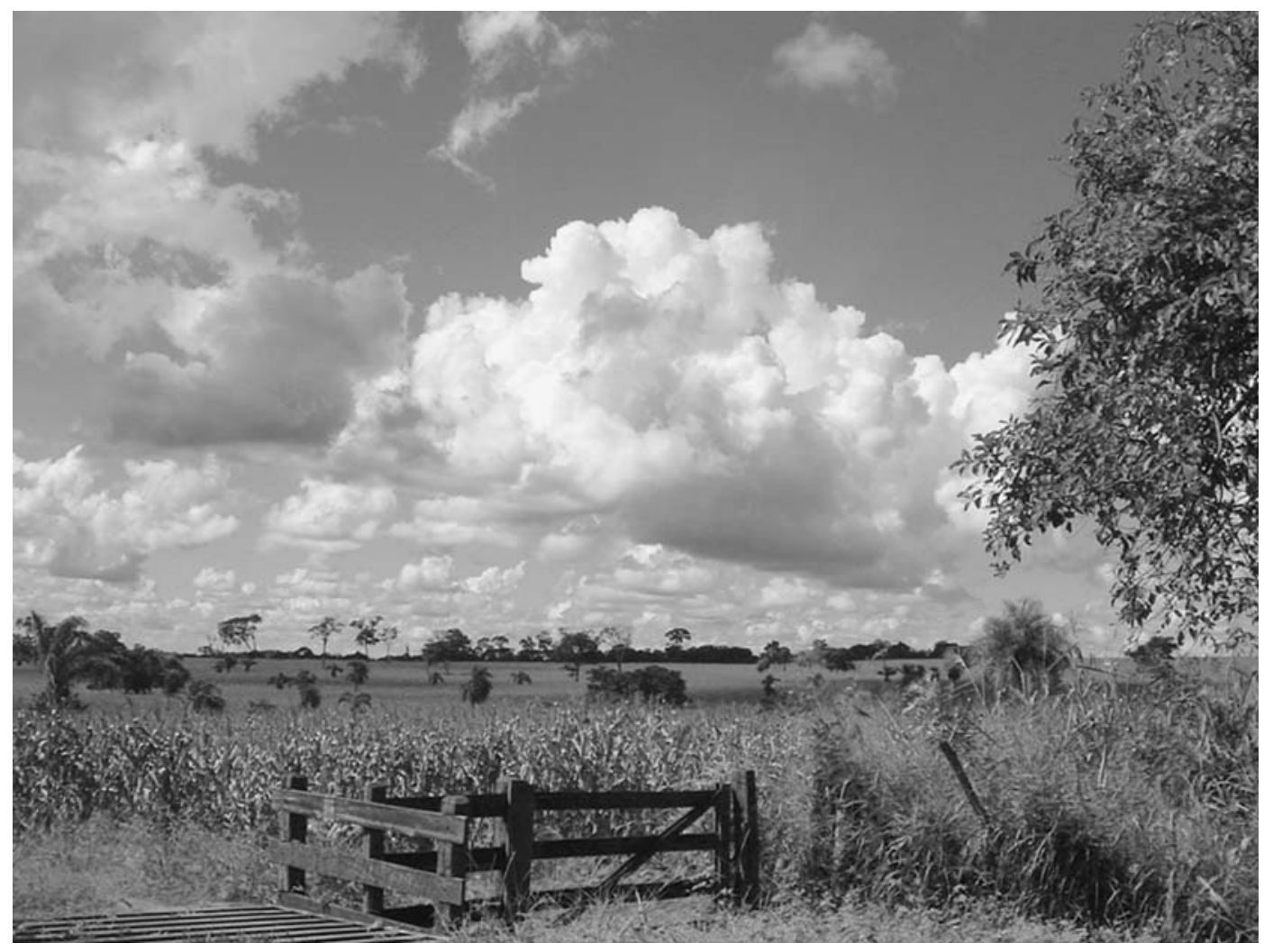

Fig. 2 - Limite entre a área pesquisada e a propriedade adjacente.

e freqüentemente vestígios arqueológicos são rarefeitos nas áreas periféricas dos sítios, considerou-se que os limites do sítio correspondem, grosso modo, com os da estação, adentrando-lhe um pouco. A partir das evidências provenientes dos poços-teste, portanto, o sítio tem aproximadamente 93m de comprimento por 77m de largura, sendo seu eixo maior o NW-SE. As peças estão enterradas a pequena profundidade, entre $15 \mathrm{~cm}$ a $20 \mathrm{~cm}$, não se encontrando qualquer tipo de vestígio arqueológico além dos fragmentos cerâmicos (Fig. 3).

Dentre os fatores de perturbação do sítio, destacam-se a fitoturbação (raízes) e a zooturbação (particularmente formigueiros, tatus e animais fuçadores). O limite sul do sítio é o já citado brejo, tendo sido encontradas peças arqueológicas inclusive nas bordas da área encharcada. Conta-se que a área já foi arada no passado; hoje, porém, além do leve desmatamento causado pela abertura da estrada e da eventual coleta oportunística de peças pelos moradores da região, não parece haver um grande impacto da ação humana sobre o sítio.
Considera-se, portanto, que o sítio cerâmico Baixadão possui bom estado de conservação.

Foram coletados apenas seis fragmentos cerâmicos - ou seja, um número pequeno, mas suficiente para fazer o diagnóstico do material. Dos seis, quatro são bordas, sendo que duas remontam. As duas restantes são paredes, isto é, fazem parte do corpo do vaso.

Todas as peças possuem manufatura roletada e antiplástico majoritariamente mineral (grãos de quartzo), com a presença minoritária de hematita. Dentre as bordas, duas chamaram a atenção por serem diagnósticas. A primeira possui decoração plástica externa na forma de uma linha incisa paralela à borda; a segunda corresponde à "forma dupla” (Fig. 4), fragmento de uma pequena tigela geminada para provável uso cerimonial bastante característico da chamada Tradição Aratu, típica do Brasil Central (Robrahn-González 1996, Prous 1992), mas também presente no norte do estado de São Paulo. Nesse sentido, a descoberta deste sítio e seu cadastramento no CNSA contribuem 


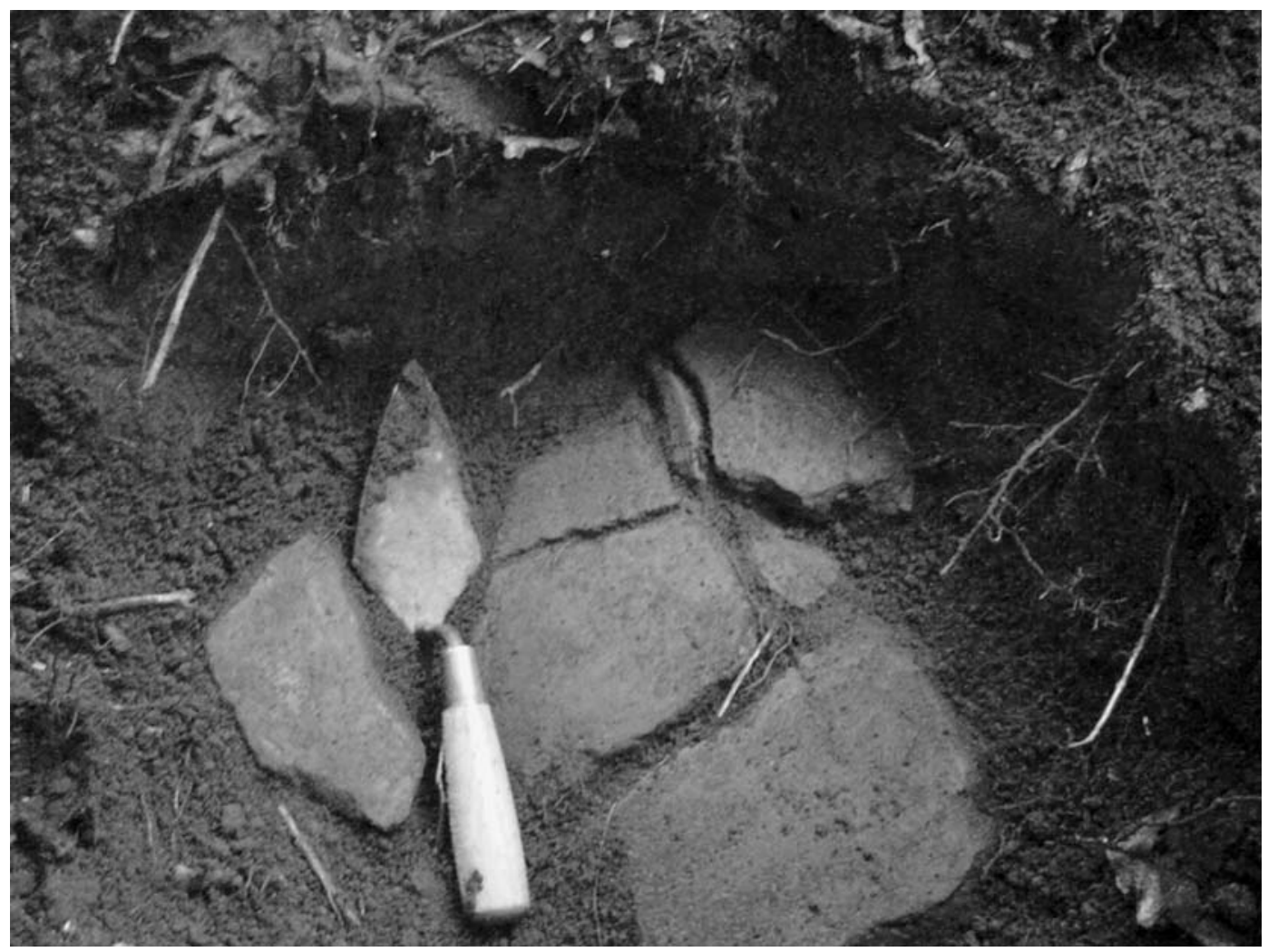

Fig. 3 - Sítio Baixadão: o material cerâmico in situ.
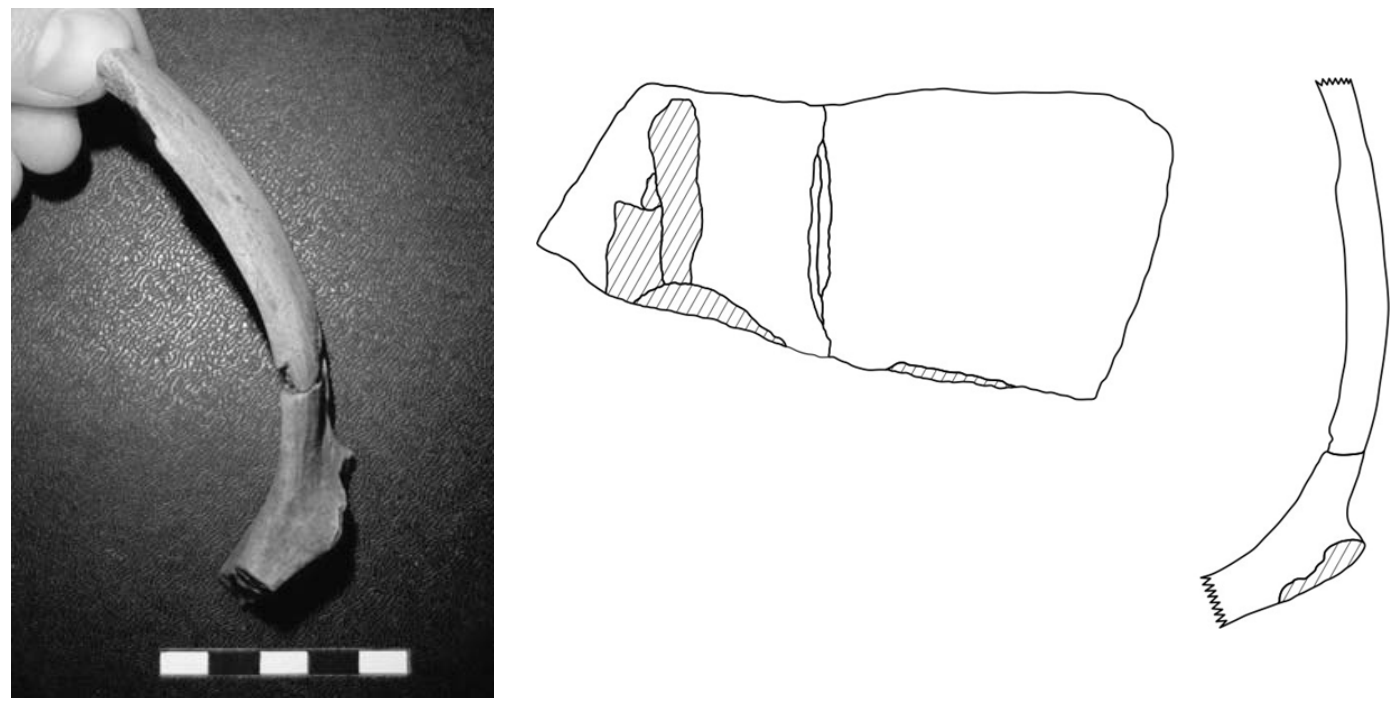

Fig. 4 - Foto e desenhos do fragmento de forma dupla. 
PENIN, A.; DE BLASIS, P.A. Sítio Baixadão: um novo sítio Aratu no norte paulista. Rev. do Museu de Arqueologia e Etnologia, São Paulo, 15-16: 449-453, 2005-2006.

para reforçar a presença vestígios associados à Tradição Aratu na porção mais meridional do Planalto Central brasileiro e alertar aos pesquisado- res do potencial arqueológico do município de Paulo de Faria e da macrorregião de São José do Rio Preto como um todo.

\section{Referências bibliográficas}

DE BLASIS, P.A.D.; PENIN, A.

2006 Diagnóstico Arqueológico Expedito na Estação Ecológica Paulo de Faria. Relatório final, não publicado.

PROUS, A.

1992 Arqueologia Brasileira. Brasília: Ed. UnB.
ROBRAHN-GONZÁLEZ, E.M.

1996 Os grupos ceramistas pré-coloniais do Centro-Oeste Brasileiro. Revista do Museu de Arqueologia e Etnologia, 6, São Paulo: 83-121.

Recebido para publicação em 11 de julho de 2006. 